\title{
GERMINAÇÃO DE SEMENTES DE NOGUEIRA-MACADÂMIA SUBMETIDAS À INCISÃO E IMERSÃO EM ÁCIDO GIBERÉLICO
}

\author{
Germination of macadamia nut seeds submitted to incision and \\ immsertion in gibberelic acid
}

\author{
Idiana Marina Dalastra ${ }^{1}$, Rafael Pio ${ }^{2}$, Fábio Albuquerque Entelmann ${ }^{3}$, \\ Tatiana Werle ${ }^{1}$, Marcelo Bortoli Uliana ${ }^{1}$, João Alexio Scarpare Filho ${ }^{3}$
}

\begin{abstract}
RESUMO
Neste trabalho, objetivou-se avaliar a emergência de plântulas de nogueira-macadâmia, por meio do uso de incisão nas sementes e imersão em ácido giberélico. Sementes do cultivar IAC-Campinas B, extraídas de frutos maduros foram padronizadas quanto ao tamanho e sanidade. Foram imergidas em recipiente preenchido por água. Em 80 sementes, realizou-se incisão de $0,5 \mathrm{~cm}$ na casca, no sentido longitudinal ao embrião, deixando as amêndoas expostas. Outras 80 sementes foram mantidas intactas. Em seguida, todas as sementes foram submersas em diferentes concentrações de ácido giberélico: $0,150,300$ e $450 \mathrm{mg} \mathrm{L}^{-1}$, por 90 horas, com sistema de oxigenação. Após esse período, as sementes foram colocadas em bandejas plásticas, entre camadas de areia grossa autoclavada, preservadas em laboratório com temperatura controlada (em torno de $25^{\circ} \mathrm{C}$ ). As bandejas foram umedecidas diariamente, com auxílio de regador manual. Após 180 dias, mensurou-se a porcentagem de emergência, os comprimentos médios das raízes, das partes aéreas e a massas secas médias totais das plântulas. Concluiu-se que a incisão e imersão de nogueira-macadâmia em ácido giberélico foram prejudiciais à emergência e desenvolvimento das plântulas.
\end{abstract}

Termos para indexação: Macadamia integrifolia, superação de dormência, fitorregulador, propagação, produção de mudas.

\begin{abstract}
The objective of the present work was to evaluate the emergency of macadamia nut seedlings through incision and immersion of the seeds in the gibberellic acid. Seeds of IAC-Campinas B cultivar, extracted from mature fruits, were standardized according to size and health. They were immerged in recipient filled with water. In 80 seeds a $0.5 \mathrm{~cm}$ incision was done in the peel, longitudinally in relation the embryo, leaving the almonds exposed. The other 80 seeds were kept intact. Soon after, the seeds were submerged in different concentrations of gibberellic acid: $0,150,300$ and $450 \mathrm{mg} \mathrm{L}^{-1}$, for 90 hours, with oxygen system. After that period, the seeds were placed in plastic trays, among layers of autoclaved sand, and preserved in laboratory with controlled temperature (around $25^{\circ} \mathrm{C}$ ). The trays were humidified daily. After 180 days, the emergency percentage, average length of the roots, average length of the aerial part and average total dry mass of the seedlings were evaluated. It was concluded that the incision and immersion of the seeds of macadamia nut gibberellic acid were harmful to the emergence and development of the seedlings.
\end{abstract}

Index terms: Macadamia integrifolia, dormancy, phytoregulator, propagation, seedlings production.

(Recebido em 15 de setembro de 2008 e aprovado em 11 de agosto de 2009)

\section{INTRODUÇÃO}

A nogueira-macadâmia (Macadamia integrifolia Maiden \& Betche), originária das florestas subtropicais australianas é, atualmente, cultivada em diversos países, a exemplo do Brasil e Estados Unidos, pela qualidade e importância nutricional dos seus frutos. Por ser de procedência subtropical, a nogueira-macadâmia desenvolve-se, adequadamente, nos Estados de São Paulo, Espírito Santo, Bahia e Rio de Janeiro, que produzem 92\% da safra nacional estimada em 3.200 toneladas de "noz em casca" (Sobierajski et al., 2005).

A nogueira-macadâmia é a principal noz cultivada no Estado de São Paulo e ocupa uma área de 2.166 ha com
199 propriedades rurais. O principal município paulista produtor é Dois Córregos, região de Jaú, seguido dos municípios de Bauru, Avaré e São Sebastião da Grama, cujas áreas de produção correspondem a $45 \%$ da área cultivada com a espécie no Estado (Barbosa et al., 2003).

Como a cultura é relativamente recente no País, estudos e dados técnicos são escassos. Poucas instituições têm investido em pesquisas com essa noz; uma das pioneiras é o Instituto Agronômico (IAC) que, desde 1948, realiza seleção de material adaptado e desenvolvimento de tecnologias para sua produção (Barbosa et al., 1991). Embora tenha sido introduzida no Brasil na década de 40 , muito dos tratos culturais

1Universidade Estadual do Oeste do Paraná/Unioeste - Marechal Cândido Rondon, PR

${ }^{2}$ Universidade Federal de Lavras/UFLA - Departamento de Agricultura/DAG - Cx. P. 3037 - 37200-000 - Lavras, MG - rafaelpio@hotmail.com

"Universidade de São Paulo, Escola Superior de Agricultura "Luiz de Queiroz" - USP/ESALQ - Departamento de Produção Vegetal - Piracicaba, SP 
empregados são, ainda, adaptações de pesquisas desenvolvidas em outros países, como Austrália e Estados Unidos (Sacramento \& Pereira, 2003).

O processo de propagação da nogueira-macadâmia é realizado por sementes, tanto para a formação de mudas de pé-franco como de porta-enxerto. Todavia, o tempo demandado para a germinação das sementes é superior a 120 dias após a semeadura, dependendo do tratamento aplicado às sementes (Simão, 1998).

Um dos grandes entraves observados na propagação da nogueira-macadâmia refere-se à reduzida porcentagem de germinação das sementes e irregularidade na emergência das plântulas, decorrentes, possivelmente, de influências do fenômeno da dormência (Hamilton, 1954).

A ocorrência de embriões imaturos e de tegumentos impermeáveis à água ou ao oxigênio, de restrições mecânicas ou de substâncias inibidoras da germinação, estão relacionadas à dormência (Bewley \& Black, 1994; Campo Dall'Orto et al., 2007; Entelmann et al., 2009). A dureza dos tecidos de cobertura as sementes, como é o caso da nogueira-macadâmia, frequentemente causam consideráveis problemas para os viveiristas, em razão da restrição à entrada de água e do oxigênio, e da resistência física à retomada do embrião (Moussa, 1998).

Entre os métodos utilizados para superação da dormência tegumentar, a escarificação mecânica é frequentemente utilizada e constitui a opção mais prática e segura para pequenos agricultores. Além de simples e de baixo custo, é eficaz para promover germinação rápida e uniforme das sementes (Hermansen, 2000). No entanto, deve ser empregada com cuidado para evitar danos a tecidos vitais das sementes e consequente redução da germinação.

Além da escarificação mecânica, a imersão em ácido giberélico das sementes de nogueira-macadâmia pode elevar os índices germinativos e uniformizar a emergência das plântulas. A giberelina, importante regulador endógeno de crescimento, produz, também, outros efeitos como indução da germinação de sementes, promoção do alongamento do hipocótilo e do caule (Peng \& Harberd, 2000; Richards et al., 2001). A ação da giberelina está relacionada à síntese de enzimas envolvidas no enfraquecimento dos tegumentos, como endo-b-manases, de expansinas e de enzimas hidrolíticas de reserva nutritiva contida no endosperma, como á-amilase. Esses eventos estão relacionados ao alongamento embrionário e à protrusão da radícula (Bewley \& Black, 1994; Bewley, 1997).

Neste trabalho, objetivou-se avaliar a emergência e desenvolvimento de plântulas de nogueira-macadâmia, em função da escarificação mecânica e da concentração de ácido giberélico aplicada às sementes.

\section{MATERIAL E MÉTODOS}

Frutos de nogueira-macadâmia 'IAC-Campinas B', provenientes de plantas matrizes situadas no município de Palotina-PR, foram coletados em março de 2007 e transportados para o Laboratório de Tecnologia de Sementes e Mudas do Centro de Ciências Agrárias, da Universidade Estadual do Oeste do Paraná (Unioeste), Marechal Cândido Rondon-PR, para a extração de suas sementes. Os carpelos foram removidos manualmente, com auxílio de faca e martelo de metal. Procedeu-se a classificação das sementes por tamanho, considerando-se, apenas, as de dimensões de dois centímetros de diâmetro e as que não sobrenadaram após imersão em recipientes com água. A amostra foi, então, dividida em duas porções de sementes. Apenas nas sementes da primeira porção foram realizadas incisões de $0,5 \mathrm{~cm}$ de comprimento na casca, com auxilio de uma serra pequena (escarificação), no sentido longitudinal ao embrião, expondo as amêndoas. A outra porção ficou intacta. Em seguida, as sementes de ambas as porções foram colocadas para embeber em Beckers, com capacidade de um litro, que continham soluções de ácido giberélico $\left(\mathrm{GA}_{3}\right)$, nas concentrações de $150,300,450 \mathrm{mg} \mathrm{L}^{-1}$, além do controle composto somente com água destilada. $\mathrm{O}$ produto utilizado foi o ProGibb, que possui em sua fórmula $10 \%$ de ácido giberélico e $90 \%$ de material inerte. Durante o período de imersão de 90 horas, as soluções foram oxigenadas mediante o emprego de bombas de aquário, segundo as recomendações de Ono et al. (1993).

Após o período de imersão, as sementes foram colocadas em bandejas plásticas ( 35 x $25 \mathrm{~cm}$ ), entre camadas de areia grossa autoclavada, mantidas em condições de ambiente de laboratório com controle da temperatura em torno de $25^{\circ} \mathrm{C}$. O umedecimento do substrato foi realizado diariamente, com auxílio de borrifador manual, sempre se aplicando $50 \mathrm{~mL}$ de água.

$\mathrm{O}$ experimento foi conduzido em esquema fatorial 2 x 4 (sementes com e sem incisão x concentrações de ácido giberélico), com quatro repetições e parcelas compostas por 20 sementes. Passados 180 dias, foram mensurados a porcentagem de emergência, os comprimentos médios das raízes e das partes aéreas, com auxílio de escalímetro, e as massas secas médias totais das plântulas, por meio da secagem do material vegetal em estufa de circulação de ar forçado à $65^{\circ} \mathrm{C}$, durante 48 horas, e posterior pesagem em balança analítica.

Os dados foram submetidos à análise de variância pelo teste $\mathrm{F}$ e as médias foram comparadas pelo teste Tukey (fator incisão), ao nível de $5 \%$ de probabilidade e à regressão linear ou quadrática (concentrações de ácido giberélico), de acordo com as indicações de Pimentel 
Gomes (2000), utilizando-se do Sistema para Análise de Variância - SISVAR (Ferreira, 2000).

\section{RESULTADOS E DISCUSSÃO}

Conforme a Tabela 1, apenas para a porcentagem de emergência de plântulas foi verificada interação entre os fatores estudado. Efeito isolado ao fator incisão das sementes foi constatado para as demais características mensuradas.

De acordo com a Figura 1, foi verificada em sementes não incisas, redução linear da emergência das plântulas de nogueira-macadâmia com a elevação da concentração da solução de imersão de ácido giberélico, da ordem de 25,51\%, quando comparada a maior concentração $\left(450 \mathrm{mg} \mathrm{L}^{-1}\right) \mathrm{em}$ relação ao tratamento controle.
A porcentagem de emergência das plântulas de nogueira-macadâmia sem qualquer tratamento $(42,13 \%)$, apresentou padrões idênticos ao relatado por Ojima et al. (1989), que obtiveram 34\% de germinação para 'IAC 5-10' e 51\% de germinação para a seleção '336 HAES'.

Os resultados não foram os esperados quanto ao emprego do ácido giberélico. O ácido giberélico, considerado ativador enzimático endógeno, promove a germinação das sementes. A aplicação exógena desse promotor influencia o metabolismo protéico e pode duplicar a taxa de síntese de proteínas das sementes (McDonald \& Khan, 1983). Segundo Khan et al. (1978), o uso de compostos químicos biologicamente ativos, como o ácido giberélico, pode sobrepujar efeitos de fatores adversos na qualidade e no desempenho das sementes.

Tabela 1 - Resumo da análise de variância para porcentagem de emergência (PE), comprimento médio da parte aérea (CMPA), comprimento médio da raiz (CMR) e massa seca média total de plântulas de nogueira-macadâmia 'IACCampinas B', em função da incisão de suas sementes e imersão em diferentes concentrações de ácido giberélico. Marechal Cândido Rondon-PR, Unioeste, 2008.

\begin{tabular}{lccccc}
\hline & \multicolumn{5}{c}{ Quadrados Médios } \\
\hline \multicolumn{1}{c}{ FV } & GL & PE & CMPA & CMR & MSMT \\
\hline Incisão (I) & 1 & $5216,78^{*}$ & $197,34^{*}$ & $585,31^{*}$ & $406,19^{*}$ \\
Concetrações de ácido giberélico (A) & 3 & $360,54^{*}$ & 100,91 & 87,36 & 22,32 \\
I x A & 3 & $299,31 *$ & 34,32 & 27,89 & 28,25 \\
Erro & 23 & 47,28 & 51,73 & 54,75 & 15,12 \\
\hline
\end{tabular}

* Significativo a $5 \%$ de probabilidade.

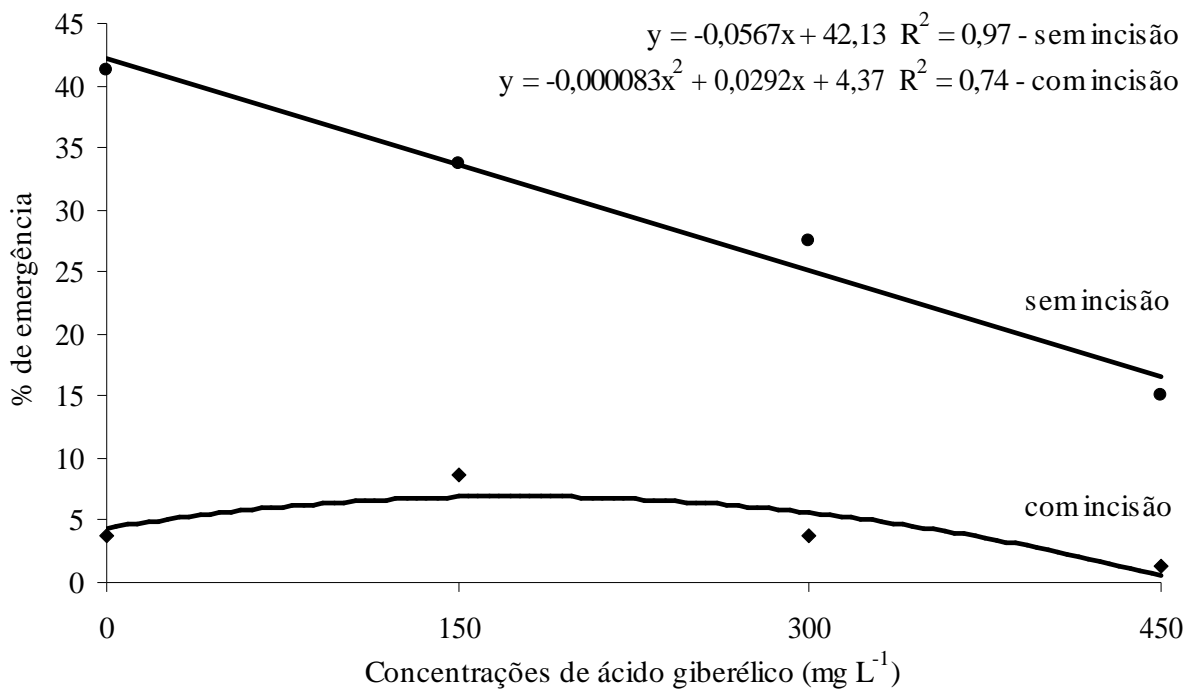

Figura 1 - Porcentagem de emergência de plântulas de nogueira-macadâmia 'IAC-Campinas B', em função da incisão de suas sementes e imersão em diferentes concentrações de ácido giberélico. Marechal Cândido Rondon-PR, Unioeste, 2008. 
O efeito do ácido giberélico sobre o alongamento celular e crescimento, destacado na literatura consultada, não foi confirmado neste trabalho. Os resultados podem ser atribuídos também às concentrações do ácido giberélico empregadas, ou mesmo ao tempo de submersão das sementes. No entanto, Ono et al. (1993), recomendam que as sementes de nogueira-macadâmia devem ser submersas em água por 90 horas, para proporcionar alta porcentagem de germinação, de acordo com os índices característicos das espécies (ao redor de 50\%).

Quanto às sementes incisas, a aplicação do ácido giberélico também mostrou-se ineficaz para incrementar a porcentagem de emergência. As porcentagens de emergência de plântulas foram bem inferiores em relação às sementes que não sofreram incisão (Figura 1).

A incisão das sementes também não foi benéfica ao desenvolvimento das plântulas de nogueiramacadâmia, pois comprimentos médios da parte aérea e das raízes e as massas secas médias totais das plântulas foram significamente inferiores nas mesmas, quando comparadas àquelas que não sofreram incisão (Tabela 2).

Os resultados obtidos no presente trabalho concordam com Rêgo et al. (1991), que compararam sementes sem e com incisão de nogueira-macadâmia e observaram que a ausência de tratamento proporcionou $52,5 \%$ de sementes germinadas após 90 dias da semeadura, $40 \%$ a mais que as sementes com incisão. Hamilton (1954) atribui a rachadura mecânica como causa de redução da germinação.

De acordo com os resultados obtidos no presente trabalho e na literatura consultada, percebe que a incisão como forma de escarificação, para a quebra de dormência das sementes de nogueira-macadâmia, não traz benefícios a emergência e desenvolvimento das plântulas. Era esperado que a incisão nas sementes, ao facilitar o contato do embrião com o ácido giberélico, promovesse melhorias significativas aos processos germinativos da nogueira-macadâmia, o que não se confirmou. Possivelmente, o contato do embrião com umidade antes de se iniciar o desencadeamento do processo germinativo possa ter prejudicado a emergência das plântulas. Segundo Malavasi (1988), a embebição demasiada das sementes de algumas espécies, reduz o período disponível para que as membranas celulares se reorganizem e, como consequência, há uma expressiva liberação de solutos, diminuindo acentuadamente a germinação.
Tabela 2 - Comprimento médio da parte aérea (CMPA), comprimento médio da raiz (CMR) e massa seca média total de plântulas (MSMT) de nogueira-macadâmia 'IACCampinas B', em função da incisão ou não de suas sementes. Marechal Cândido Rondon-PR, Unioeste, 2008.

\begin{tabular}{lccc}
\hline \multirow{2}{*}{$\begin{array}{c}\text { Incisão na } \\
\text { semente }\end{array}$} & \multicolumn{4}{c}{ Variáveis analisadas* } \\
\cline { 2 - 4 } & $\begin{array}{c}\text { CMPA } \\
(\mathrm{cm})\end{array}$ & $\begin{array}{c}\text { CMR } \\
(\mathrm{cm})\end{array}$ & $\begin{array}{c}\text { MSMT } \\
(\mathrm{mg})\end{array}$ \\
\hline Sem incisão & 12,58 a & $17,72 \quad \mathrm{a}$ & $12,48 \mathrm{a}$ \\
Com incisão & $7,53 \quad \mathrm{~b}$ & $9,02 \quad \mathrm{~b}$ & $5,24 \quad \mathrm{~b}$ \\
C.V. (\%) & 22,18 & 23,41 & 24,74 \\
\hline
\end{tabular}

*Médias seguidas pela mesma letra na coluna não diferem significamente entre si, pelo teste Tukey, ao nível de 5\% de probabilidade.

Novos estudos devem ser realizados com a nogueiramacadâmia, não só no que tange o processo germinativo de suas sementes, mas também técnicas auxiliares que venham a facilitar o enraizamento de suas estacas (Chagas et al., 2008; Bastos et al., 2009; Ohland et al., 2009).

\section{CONCLUSÃO}

A imersão de sementes de nogueira-macadâmia em ácido giberélico por 90 horas prejudica a emergência das plântulas. A incisão, como forma de escarificação, diminui significamente a porcentagem de emergência e desenvolvimento das plântulas.

\section{REFERÊNCIAS BIBLIOGRÁFICAS}

BASTOS, D. C.; SCARPARE FILHO, J. A.; LIBARDI, M. N.; PIO, R. Estiolamento, incisão na base da estaca e uso de ácido indolbutírico na propagação da caramboleira por estacas lenhosas. Ciência e Agrotecnologia, Lavras, v. 33, n.1, p. 313-318, jan./fev., 2009.

BARBOSA, W.; CAMPO-DALL'ORTO, F.A.; OJIMA, M.; SANTOS, R.R.; FRANCO, J.A.M. Seleções de nogueira-macadâmia do Instituto Agronômico. O Agronômico, Campinas, n.43, p.94-99, 1991.

BARBOSA, W.; POMMER, C.V.; RIBEIRO, M.D.; VEIGA, R.F.A.; COSTA, A.A. Distribuição geográfica e diversidade varietal de frutíferas e nozes de clima temperado no Estado de São Paulo. Revista Brasileira de Fruticultura, Cruz das Almas, v.25, n.2, p.341-344, 2003.

BEWLEY, J.D. Breaking dow the walls: a role for endo betamananase in release from seed dormancy. Plant Science, Shannon, v.2, p.139-144, 1997. 
BEWLEY, J.D.; BLACK, M. Seeds: physiology of development and germination. New York: Plenum, 1994. 445p.

CHAGAS, E. A.; PIO, R.; BETTIOL NETO, J. E.; SOBIERAJSKI, G. da R.; CAMPO DALL'ORTO, F. A.; SIGNORINI, G. Enraizamento de estacas lenhosas de pessegueiro e clones de umezeiros submetidos à aplicação de AIB. Ciência e Agrotecnologia, Lavras, v. 32, n.3, p. 986-991, maio/jun., 2008.

DALL'ORTO, F. A. C.; OJIMA, M.; PIO, R.; CHAGAS, E. A. Avaliação da capacidade reprodutiva de algumas cultivares de marmeleiros visando a obtenção de portaenxertos. Ciência e Agrotecnologia, Lavras, v.31, n.2, p.274-278, mar./abr., 2007.

ENTELMANN, F. A.; PIO, R.; CHAGAS, E. A., SCARPARE FILHO, J. A.; ALVARENGA, A. A.; ABRAHÃO, E. Estratificação à frio de sementes de 'Japonês', portaenxerto para marmeleiros. Ciência e Agrotecnologia, Lavras, v.33, Edição Especial, p.1877-1882, 2009.

FERREIRA, D.F. Análise estatística por meio do SISVAR (Sistema para Análise de Variância) para Windows versão 4.0. In: REUNIÃO ANUAL DA REGIÃO BRASILEIRA DA SOCIEDADE INTERNACIONAL DE BIOMETRIA, 45., 2000, São Carlos. Anais... São Carlos: UFSCar, 2000. p.255-258.

HAMILTON, R.A. Make your own nutcracker. Hawaii Farm Science, v.3, n.2, p.5-6, 1954.

HERMANSEN, L.A. Pretreatments to overcome seed coat dormancy in Dimorphandra mollis. Seed Science \& Technology, Zurich, v.28, n.1, p.581-595, 2000.

KHAN, A.A. Incorporation of bioactive chemicals into seeds to alleviate environmental stress. Acta

Horticulturae, The Hague, v.83, n.2, p.2255-2264, 1978.

MALAVASI, M.M. Germinação de sementes. In: Manual de análise de sementes florestais. Piracicaba: Fundação Cargill, 1988. 100p.

McDONALD, M.D.; KHAN, A.A. Acid scarification and protein synthesis during seed germination. Agronomy Journal, Madison, v.2, n.75, p.111-114, 1983.

MOUSSA, H. Factors affecting the germination of doum palm (Hyphaene thebaica Mart.) seeds from the semi- arid of Niger, West Africa. Forest Ecology and Management, Amsterdam, v.104, n.1, p.27-34, 1998.

OHLAND, T.; PIO, R.; CHAGAS, E. A.; BARBOSA, W.; KOTZ, T. E.; DANELUZ, S. Enraizamento de estacas apicais de figueira 'Roxo de Valinhos' em função de época de coleta e AIB. Ciência e Agrotecnologia, Lavras, v. 33, n.1, p. 74-78, jan./fev., 2009.

OJIMA, M.; CAMPO DALL'ORTO, F.A.; RIGITANO, O. Germinação de sementes de nogueira-macadâmia. 2.ed. Campinas: Instituto Agronômico, 1989. 17p. (Boletim técnico, 33).

ONO, E.O.; RODRIGUES, J.D.; SABINO, J.C.; PINHO, S.Z. Estudos da imersão e da viabilidade de sementes de macadâmica (Macadamia integrifolia Maiden \& Betche). Scientia Agrícola, Piracicaba, v.50, n.1, p.40-44, 1993.

PENG, J.; HARBERD, N.P. The role of GA-mediated signalling in the control of seed germination. Current Opinion in Plant Biology, London, v.5, p.376-381, 2000.

PIMENTEL GOMES, F. Curso de estatística experimental. 14.ed. Piracicaba: USP/ESALQ, 2000. 477p.

RÊGO, F.A.O.; COSTA, M.M.M.N.; ABREU, S.M.; SILVA, A.Q.; SILVA, H. Influência do tamanho da semente e escarificação na germinação da macadâmia (Macadamia integrifolia). Informativo ABRATES, Londrina, v.1, n.4, p.85, 1991.

RICHARDS, D.E.; KING, K.E.; AIT-ALI, T.; HARBERD, N.P. How gibberellin regulates plant growth and development: a molecular genetic analysis of gibberellin signaling. Annual Review of Plant Physiology and Plant Molecular Biology, Dordrecht, v.52, p.67-88, 2001.

SACRAMENTO, C.K.; PEREIRA, F.M. Fenologia da floração da nogueira-macadâmia (Macadamia integrifolia Maiden \& Betche) nas condições climáticas de Jaboticabal, São Paulo, Brasil. Revista Brasileira de Fruticultura, Cruz das Almas, v.25, n.1, p.19-22, 2003.

SIMÃO, S. Tratado de fruticultura. Piracicaba: FEALQ, 1998. 760p.

SOBIERAJSKI, G.R.; FRANCISCO, V.L.F.S.; ROCHA, P.; GHILARDI, A.A.; MAIA, M.L. Noz-macadâmia: produção, mercado e situação no Estado de São Paulo. Informações Econômicas, São Paulo, v.36, n.5, p.25-36, 2005. 